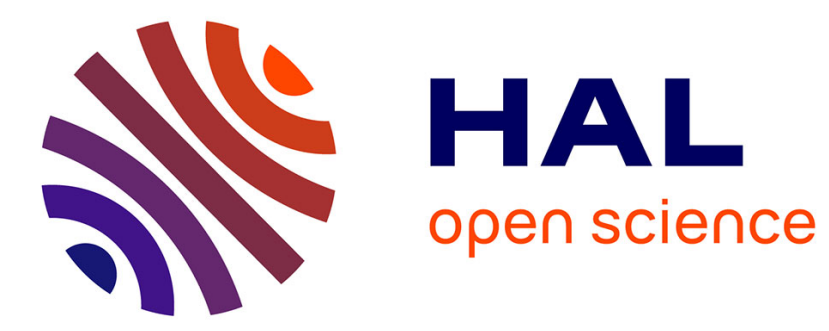

\title{
Sound absorption by green walls at normal incidence: physical analysis and optimization
}

\author{
Emmanuel Attal, Nicolas Côté, Takafumi Shimizu, Bertrand Dubus
}

\section{To cite this version:}

Emmanuel Attal, Nicolas Côté, Takafumi Shimizu, Bertrand Dubus. Sound absorption by green walls at normal incidence: physical analysis and optimization. Acta Acustica united with Acustica, 2019, 105 (2), pp.301-312. 10.3813/AAA.919313 . hal-02356531

\section{HAL Id: hal-02356531 \\ https://hal.science/hal-02356531}

Submitted on 30 Jul 2021

HAL is a multi-disciplinary open access archive for the deposit and dissemination of scientific research documents, whether they are published or not. The documents may come from teaching and research institutions in France or abroad, or from public or private research centers.
L'archive ouverte pluridisciplinaire HAL, est destinée au dépôt et à la diffusion de documents scientifiques de niveau recherche, publiés ou non, émanant des établissements d'enseignement et de recherche français ou étrangers, des laboratoires publics ou privés. 


\title{
Sound absorption by green walls at normal incidence: physical analysis and optimization
}

\author{
Emmanuel Attal ${ }^{1)}$, Nicolas Côté ${ }^{1,2)}$, Takafumi Shimizu ${ }^{3)}$, Bertrand Dubus ${ }^{1)}$, \\ 1) Univ Lille, CNRS, Ecole Centrale, ISEN, Univ Valenciennes, IEMN, UMR 8520 \\ 59046 Lille cedex, France. bertrand.dubus@isen.fr \\ 2) Wavely, 59652 Villeneuve d'Ascq, France. \\ 3) Central Research Laboratory, Daiwa House Industry Co, Nara City, Japan.
}

\section{Summary}

$$
\begin{aligned}
& \text { Sound absorption by different green wall systems at } \\
& \text { normal incidence is investigated between } 100 \text { and } 1000 \\
& \text { Hz. Measurements are conducted in an impedance } \\
& \text { tube in order to estimate the effective acoustic prop- } \\
& \text { erties of plants and soils. Using these properties, the } \\
& \text { transfer matrix method is employed to simulate ab- } \\
& \text { sorption coefficient and surface impedance of multi- } \\
& \text { layer green wall geometries. Results show that an } \\
& \text { adequate choice of layer geometries may result in an } \\
& \text { efficient sound absorption in a broad frequency range } \\
& \text { due to two main mechanisms: thickness resonances } \\
& \text { of the wall structure and quarter wave transformer } \\
& \text { effect of plant layer between air and soil media. To } \\
& \text { optimize the absorption bandwidth of green facade, } \\
& \text { continuous living wall system or modular living wall } \\
& \text { system, effect of plant, soil or air layer thicknesses } \\
& \text { on simulated absorption coefficient are also provided. } \\
& \text { With a } \mathbf{1 6} \text { cm thick optimized system, average } \\
& \text { absorption coefficients typically reach } \mathbf{0 . 2} \text { be- } \\
& \text { tween } \mathbf{3 0 0} \text { and } \mathbf{1 0 0 0} \mathbf{H z} \text { for a green facade, } \mathbf{0 . 2} \\
& \text { between } \mathbf{2 0 0} \text { and } \mathbf{1 0 0 0} \mathbf{H z} \text { for a continuous liv- } \\
& \text { ing wall system and } \mathbf{0 . 9} \text { between } \mathbf{3 0 0} \text { and } \mathbf{1 0 0 0} \\
& \text { Hz for a modular living wall system. }
\end{aligned}
$$

\section{Introduction}

Green walls are installed in urban areas to introduce more vegetation without occupying any space at street level. When applied in a significant urban scale, they may contribute to urban biodiversity [1], air quality [2], temperature reduction and mitigation of the heat island effect [3] and acoustic protection [4]. Buildings and roads are made of acoustically rigid materials (asphalt, brick, concrete, glazing, ...) which reflect sound emitted from road traffic and therefore strongly amplify environmental noise. In that context, building envelope greening was found to be an efficient solution for different noise issues in cities: use of green roofs to attenuate sound propagating above buildings from streets toward courtyards [5]; significant traffic noise reduction with vegetated low-height noise barriers placed close to the driving lanes [6]; Abatement of noise reflection by facade in narrow urban streets in the presence of green wall systems [5].

Green walls can be subdivided in two main systems: green facades are ground based systems made of plants climbing along a wall ; living walls are nonground based systems involving a frame and a support and allowing the use of a wider variety of plants [7]. The former falls into two categories: continuous living wall systems and modular living wall systems. In continuous living wall systems, the frame is fixed to the wall. An air gap is kept between the frame and the building wall to bring natural ventilation and protect against humidity. The frame is usually covered with layers of permeable and root proof screens forming pockets for the introduction of plants without substrate. Modular living wall systems are composed of several connected elements made of polymeric material containing both plants and a substrate made of organic or/and inorganic compounds where the roots can proliferate. They often have a flat backing surface which is directly fixed on the building surface. A schematic representation of these green wall systems is displayed in Figure 1. Green façade geometry is composed of a single layer of plants fixed on a building wall (idealized by a rigid backing condition). In continuous living wall system, the plant layer fixed on a support is separated from the building wall by an air gap. Type I modular living wall system is made of a plant layer atop a substrate layer directly mounted on a building wall. Finally, in type II modular living wall system, plant and soil layers are separated from building wall surface by an air gap.

Acoustic characterizations of green walls have been conducted both in situ $[4,8]$ and in reverberant rooms $[4,8,9]$. Insertion loss measurements performed in situ by Wong et al on types I and II modular living wall systems [4] displayed a strong dependence upon thickness of plants and substrate constituents in the audible frequency range. Sound absorption coefficient 


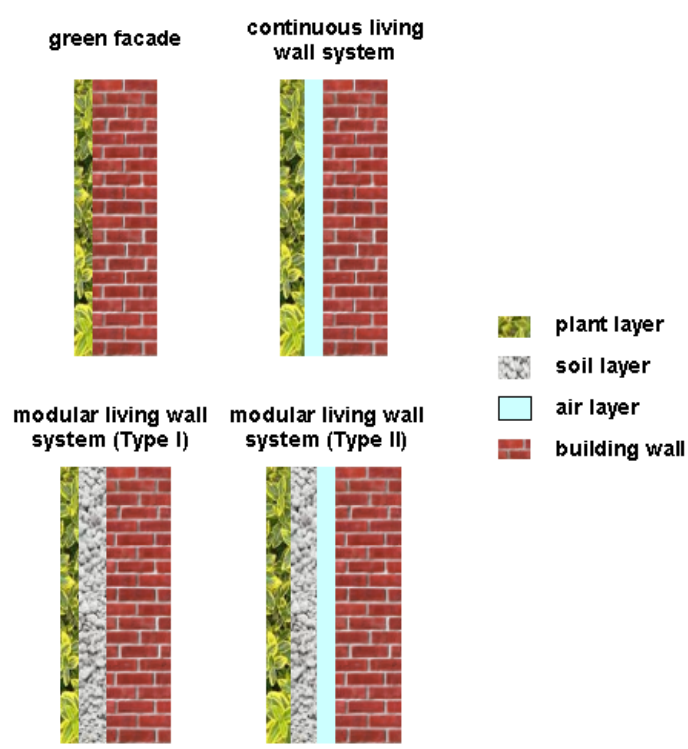

Figure 1: Schematic representation of different green wall systems

averaged for all incident angles was also measured in reverberant room using the ISO standard method [10]. For living wall system thicknesses varying between 9 and $48 \mathrm{~cm}$, they reported average sound absorption coefficients between 0.3 and 0.5 for frequencies ranging from $300 \mathrm{~Hz}$ to $5 \mathrm{kHz}$. Such values were found higher than those measured for commonly used building materials such as brick, concrete or glass. Smaller values, between 0.05 and 0.3 , were measured below $300 \mathrm{~Hz}$. Shimizu et al demonstrated that insulation performance of a steel noise barrier may be improved by 0.5 to $5.5 \mathrm{~dB}$ when installing a type II living wall system [8]. They reported average absorption coefficient higher than 0.75 between $100 \mathrm{~Hz}$ and $1.6 \mathrm{kHz}$ for this system. Sound reduction index measurement performed by Azkorra et al [9] showed that reduction of airborne noise with Type II living wall system is lower than those of common constructive solutions such as brick or thermal double glazing. Average absorption coefficient of their system was found similar to Wong's results [4] above 300 $\mathrm{Hz}$ and much higher, between 0.4 and 0.5 , below 300 $\mathrm{Hz}$.

Laboratory measurements have been realized separately on plants and soils to improve the understanding of sound absorption by green wall systems. As stated before, all incidence average absorption coefficient is measured in a reverberant room [10], while normal incidence absorption coefficient is characterized in an impedance tube [11]. Yang et al provided average absorption coefficients for different configurations: soil, plants and soil covered by plants with thicknesses varying between 9 and $30 \mathrm{~cm}$ for plants and between 5 and $20 \mathrm{~cm}$ for soils [12]. They showed that sound absorption by plants is negligible below $400 \mathrm{~Hz}$. Conversely, average absorption coefficient of soil is moderate (between 0.25 and 0.5 ) below $200 \mathrm{~Hz}$ and high (between 0.5 and 0.9 ) above $200 \mathrm{~Hz}$ and decreases with moisture content. A maximum value of 0.9 was obtained at $1 \mathrm{kHz}$. The effect of plant coverage over a soil was found to be frequency dependent $[13,14,15,16,17]$ : average absorption coefficient increases below $2 \mathrm{kHz}$ and decreases above $2 \mathrm{kHz}$. Normal-incidence absorption coefficient was studied by Horoshenkov et al [13] and Benkreira et al [14] for similar configurations including five types of plants and two different soils. As in reference [12], they observed that a foliage layer placed above a soil may lead to a significant increase of acoustic absorption coefficient in a broad frequency range for normal incidence [13]. This result was correlated to leaf area density and orientation but the underlying physical phenomenon remained unclear. Ding et al [15] reported measurements and Finite Difference Time Domain simulations of sound absorption by porous substrates covered by a single leaf. As in [12], they found that leaf coverage increases sound absorption below 2 $\mathrm{kHz}$ and decreases it beyond $2 \mathrm{kHz}$. Attal et al [17] characterized the effective speed of sound and characteristic impedance of plant and soil samples separately and used the transfer matrix method in order to calculate normal incidence absorption coefficient of plant, soil and plant-soil samples of different thicknesses. They found that quarter wavelength resonance of the sample influences greatly sound absorption spectrum for rigid backing condition.

In order to improve the physical understanding of sound absorption by green wall systems, this work provides measurements carried out in an impedance tube on plants and soil samples separately in order to determine their effective speed of sound and characteristic impedance. These experimental results are then used to calculate the normal incidence absorption coefficient of composite samples made of plants, soil and air layers using the Transfer Matrix Method. The experimental setup is described in section 2. Measurement of intrinsic properties of plants and soils are reported in sections 3 and 4 respectively. Finally, sound absorption at normal incidence is studied in section 5 for the different green wall systems displayed in Figure 1. Simulation method is validated by comparing calculated and measured absorption coefficients. Variation of sound absorption with plants, soil and/or air gap thicknesses is provided for each green wall system. 


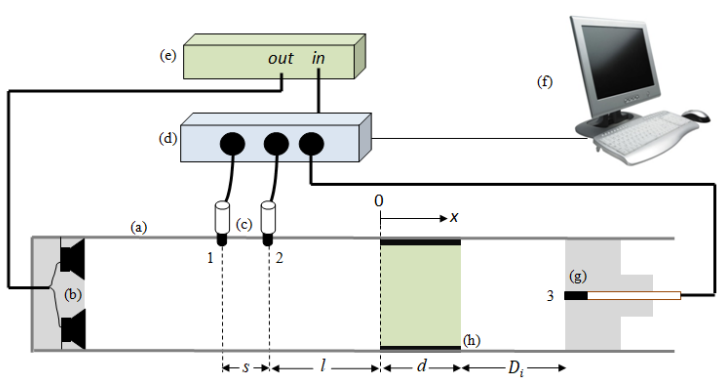

Figure 2: Schematic view of the experimental setup: (a) stainless steel tube; (b) cylindrical PVC disk integrating 4 loudspeakers; (c) microphones; (d) sound card; (e) amplifier; (f) computer; (g) flush mounted microphone on movable piston; (h) sample holder containing the sample.
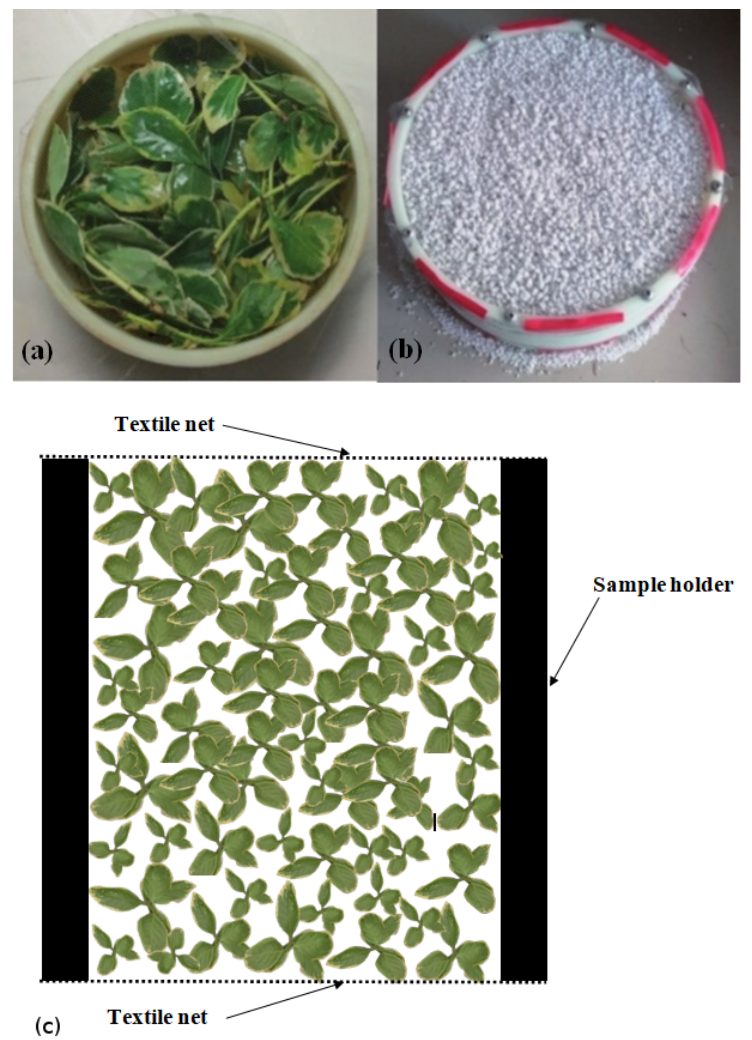

Figure 3: (a) Japanese spindle sample. (b) Perlite sample. (c) Schematic view of plant in sample holder.

\section{Experimental setup and mea- surement method}

Acoustic characterization of samples is performed in an impedance tube using the three-microphone twoload method $[18,19,20]$. The impedance tube of circular cross section (length $1.9 \mathrm{~m}$, inner diameter $192 \mathrm{~mm}$, wall thickness $15 \mathrm{~mm}$ ) is made of stainless steel. Thus, a diameter significantly larger than sample heterogeneities (leaves, stones...) is used [17]. Four broadband loudspeakers (type Visaton FRS) are mounted in the PVC front disk located at the front end of the tube. A movable Teflon piston (axial thickness $61 \mathrm{~mm}$ )is positionned at the other end. It is assumed to be acoustically rigid. A plastic sample holder (axial thickness $16 \mathrm{~cm}$ ) contains plants or soil maintained by two pieces of textile net. Acoustic pressure measurements are performed with three microphones (Sennheiser MKE 2P with $3.8 \mathrm{~mm}$ diameter). Two microphones are located in front of the sample respectively at 80 and $90 \mathrm{~cm}$ from the front end of the tube (Fig. 2). According to [11], the lowest frequency of measurement corresponds to an acoustic wavelength in air equal to one hundredth of microphone separation distance i.e. $34 \mathrm{~Hz}$ for the considered geometry. The third microphone is located at the center of the movable piston behind the sample. The sound card (RMEFireface 802) control inputs and outputs of the system. The excitation signal is a step by step sine.

Measurement method is based on plane wave assumption in the tube which is theoretically verified up to $1037 \mathrm{~Hz}$ in air. This upper frequency bound decreases when speed of sound in sample material is lower than speed of sound in air. As indicated in ISO 10534-2 standard [11], the minimal distance between sample surface and the closest microphone is larger than tube diameter in all experiments to retrieve a plane wave front at the microphone positions. After calibrating each microphone using [21], the sample under test (thickness $d$ ) is inserted at a fixed position inside the tube. Then, transfer functions $H_{m n}\left(D_{i}\right)$ between microphones $m$ and $n(1 \leq m \leq 3,1 \leq n \leq 3, m \neq \mathbf{n})$ are measured for backing cavity lengths $D_{i}(1 \leq i \leq 2)$. Assuming $e^{+j \omega t}$ time dependency where $\omega$ is the circular frequency and $t$ the time, acoustic pressure $P_{i}(x)$ and velocity $V_{i}(x)$ on sample front $(x=0)$ and back $(x=d)$ surfaces are written for backing cavity $i$

$$
\begin{gathered}
P_{i}(0)=-2 j e^{j k_{0} l} \frac{H_{12}\left(D_{i}\right) \sin \left(k_{0}(l+s)\right)-\sin \left(k_{0} l\right)}{H_{12}\left(D_{i}\right) e^{j k_{0} s}-1}, \\
V_{i}(0)=\frac{2 j e^{j k_{0} l}}{Z_{0}} \frac{H_{12}\left(D_{i}\right) \cos \left(k_{0}(l+s)\right)-\cos \left(k_{0} l\right)}{H_{12}\left(D_{i}\right) e^{j k_{0} s}-1}, \\
P_{i}(d)=-2 j e^{j k_{0} l} \frac{H_{13}\left(D_{i}\right) \sin \left(k_{0} s\right) \cos \left(k_{0} D_{i}\right)}{H_{12}\left(D_{i}\right) e^{j k_{0} s}-1},
\end{gathered}
$$

\section{0} 171 


$$
V_{i}(d)=\frac{2 j e^{j k_{0} l}}{Z_{0}} \frac{H_{13} \sin \left(k_{0} s\right) \sin \left(k_{0} D_{i}\right)}{H_{12}\left(D_{i}\right) e^{j k_{0} s}-1},
$$

where $\rho_{0}, c_{0}$ and $Z_{0}=\rho_{0} c_{0}$ are air density, speed of sound and characteristic impedance respectively and $k_{0}=\omega / c_{0}$ is the acoustic wave number. Sample transfer matrix $\mathbf{T}(\omega)$ is written as

$$
\left[\begin{array}{l}
P_{i}(0) \\
V_{i}(0)
\end{array}\right]=\left[\begin{array}{ll}
T_{11}(\omega) & T_{12}(\omega) \\
T_{21}(\omega) & T_{22}(\omega)
\end{array}\right]\left[\begin{array}{l}
P_{i}(d) \\
V_{i}(d)
\end{array}\right] .
$$

Expressions of Eq. (5) for backing cavity $i=1$ and $i=2$ are combined in a $4 \times 4$ matrix

$$
\left[\begin{array}{l}
P_{1}(0) \\
V_{1}(0) \\
P_{2}(0) \\
V_{2}(0)
\end{array}\right]=\left[\begin{array}{cccc}
T_{11}(\omega) & T_{12}(\omega) & 0 & 0 \\
T_{21}(\omega) & T_{22}(\omega) & 0 & 0 \\
0 & 0 & T_{11}(\omega) & T_{12}(\omega) \\
0 & 0 & T_{21}(\omega) & T_{22}(\omega)
\end{array}\right]\left[\begin{array}{c}
P_{1}(d) \\
V_{1}(d) \\
P_{2}(d) \\
V_{2}(d)
\end{array}\right]
$$

From Eq. (6), elements of $\mathbf{T}(\omega)$

$$
\begin{aligned}
T_{11}(\omega) & =\frac{P_{1}(0) V_{2}(d)-P_{2}(0) V_{1}(d)}{P_{1}(d) V_{2}(d)-P_{2}(d) V_{1}(d)}, \\
T_{12}(\omega) & =\frac{P_{1}(d) P_{2}(0)-P_{1}(0) P_{2}(d)}{P_{1}(d) V_{2}(d)-P_{2}(d) V_{1}(d)}, \\
T_{21}(\omega) & =\frac{V_{1}(0) V_{2}(0)-V_{1}(d) V_{2}(0)}{P_{1}(d) V_{2}(d)-P_{2}(d) V_{1}(d)}, \\
T_{22}(\omega) & =\frac{P_{1}(d) P_{2}(0)-P_{1}(0) P_{2}(d)}{P_{1}(d) V_{2}(0)-P_{2}(d) V_{1}(0)},
\end{aligned}
$$

are determined using the transfer functions measured between the microphones.

Assuming that the sample may be described as an effective ideal fluid medium, $\mathbf{T}(\omega)$ is written as

$$
\left[\begin{array}{ll}
T_{11}(\omega) & T_{12}(\omega) \\
T_{21}(\omega) & T_{22}(\omega)
\end{array}\right]=\left[\begin{array}{cc}
\cos \left(k_{c} d\right) & j Z_{c} \sin \left(k_{c} d\right) \\
\frac{j \sin \left(k_{c} d\right)}{Z_{c}} & \cos \left(k_{c} d\right)
\end{array}\right],
$$

where $k_{c}=\omega / c$ and $Z_{c}$ are respectively the characteristic wave number and the characteristic impedance of the material constituting the sample. $c$ is the effective speed of sound in the sample. $k_{c}, Z_{c}$ and $c$ are deduced from the transfer measured matrix using

$$
\begin{gathered}
k_{c}(\omega)=\frac{\arccos \left(T_{11}(\omega)\right)}{d}, \\
c(\omega)=\frac{\omega}{k_{c}(\omega)}, \\
Z_{c}(\omega)=\sqrt{\frac{T_{12}(\omega)}{T_{21}(\omega)}} .
\end{gathered}
$$

Finally, the absorption coefficient $\alpha(\omega)$ and the surface impedance $Z_{s}(\omega)$ of the sample in rigid backing condition are obtained using

$$
\begin{gathered}
\alpha(\omega)=1-\left|\frac{T_{11}(\omega)-Z_{0} T_{21}(\omega)}{T_{11}(\omega)+Z_{0} T_{21}(\omega)}\right|^{2}, \\
Z_{s}(\omega)=\frac{T_{11}(\omega)}{T_{21}(\omega)} .
\end{gathered}
$$

\section{Measurement of plant sam- ${ }^{218}$ ples}

Japanese spindle is an evergreen small shrub with oval leaves which are about $5 \mathrm{~cm}$ long and $3 \mathrm{~cm}$ wide (Fig. 3 a). The sample is constituted by a set of small branches introduced in the sample holder (Fig 3.c). The foliage is disposed in the whole volume of the sample holder to obtain the most homogeneous distribution possible. A sheet of tulle with fine mesh is added on the top and bottom of the sample holder to keep the air/plants interface perpendicular to tube axis. The tulle net on the top side is assumed to be the front surface of the sample. Japanese spindle is chosen for several reasons: its is largely available; its leaves are small compared to tube diameter; its foliage is not altered when separated from the trunk during three days; its foliage is compact and thick allowing for samples of lower porosity and larger thickness. The experimental results are reported for 8 and $16 \mathrm{~cm}$ thick samples made of Japanese spindle plants with a porosity of $95 \%$. Porosity is evaluated by dividing the total volume of the branches (obtained by submerging the branches in a water tank and measuring the water level variation) by the internal volume of the sample holder. Measurements made in winter on japanese shrubs indicate an average foliage thickness of $20 \mathrm{~cm}$ and an average porosity of $97 \%$. Foliage porosity is inhomogeneous and increases when moving away from the source of light. Acoustic measurements are performed for four different geometrical arrangements of the same branches.

Figure 4 displays the real part of the effective speed of sound, the imaginary part of the acoustic wave number (attenuation) and the real part of the characteristic impedance versus frequency. Above 250 $\mathrm{Hz}$, spindle plants behaves as a nondispersive medium having an almost constant speed of sound of $250 \mathrm{~m} / \mathrm{s}$, a slowing down of approximately $25 \%$ with respect to air speed of sound. Attenuation increases monotonically but remains weak with a maximum value of 1 $\mathrm{Np} / \mathrm{m}$ at $1000 \mathrm{~Hz}$. The mean value of the real part of the characteristic impedance is about 620 Rayl in the $300-1000 \mathrm{~Hz}$ frequency range, a value corresponding to a $50 \%$ increase with respect to air characteristic impedance. Similar measured values are obtained with 8 and $16 \mathrm{~cm}$ thick samples. Some discrepancies are observed when the standard deviation between measurements becomes high: below $200 \mathrm{~Hz}$ for 8 and $16 \mathrm{~cm}$ thick samples and between 680 and $880 \mathrm{~Hz}$ for $16 \mathrm{~cm}$ thick samples. As attenuation is weak in plant sample, some elements of $\mathbf{T}(\omega)$ get close to zero when $k d \approx n \pi / 2$. At these frequencies, inversion procedure becomes sensitive to small changes in 
(a)

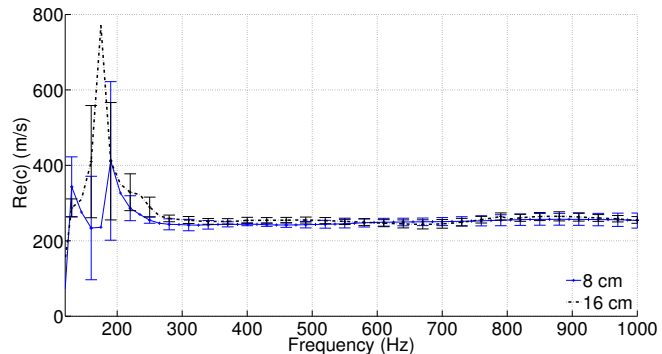

(b)

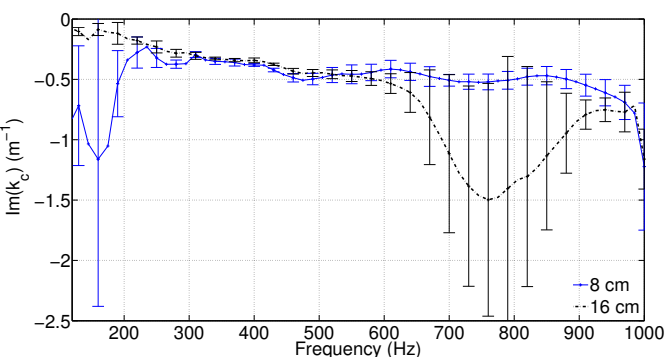

(c)

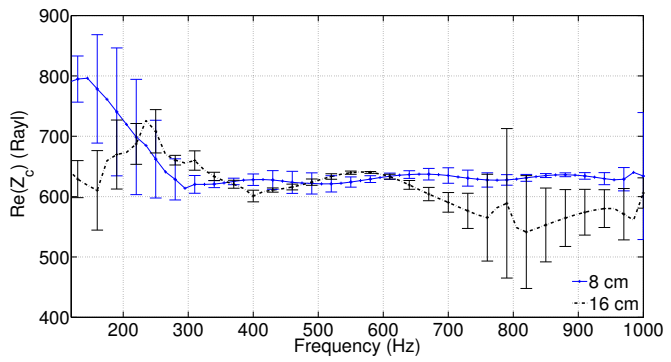

Figure 4: 8 and $16 \mathrm{~cm}$ thick Japanese spindle samples with $95 \%$ porosity: (a) real parts of effective speed of sound; (b) imaginary part of acoustic wavenumber; (c) real part of non-normalized characteristic impedance. Quantities measured in an impedance tube. Full line: average value; error bars: standard deviation.

sample geometry or small errors on phase measurements.

Frequency spectra of the absorption coefficient and the surface impedance modulus of Japanese spindle samples in rigid backing condition are given in Figure 5. Variation of the surface impedance modulus versus frequency displays minima associated to the quarterwavelength resonance of the sample at $781 \mathrm{~Hz}$ for $d=$ $8 \mathrm{~cm}$ and $391 \mathrm{~Hz}$ for $d=16 \mathrm{~cm}$ for a speed of sound of $250 \mathrm{~m} / \mathrm{s}$. Maximum of the surface impedance modulus (antiresonance) at $781 \mathrm{~Hz}$ coincides with halfwavelength resonance of $16 \mathrm{~cm}$ thick sample. Due to weak attenuation (Fig. 4b), acoustic absorption remains relatively low $(<0.35)$ in the whole frequency range. These values are close to previously published measurements of plant samples having similar porosity and thickness [13]. Highest absorption coefficients are obtained near sample quarter wave resonance where a better matching is obtained between the surface impedance of the sample and air characteristic impedance. (a)
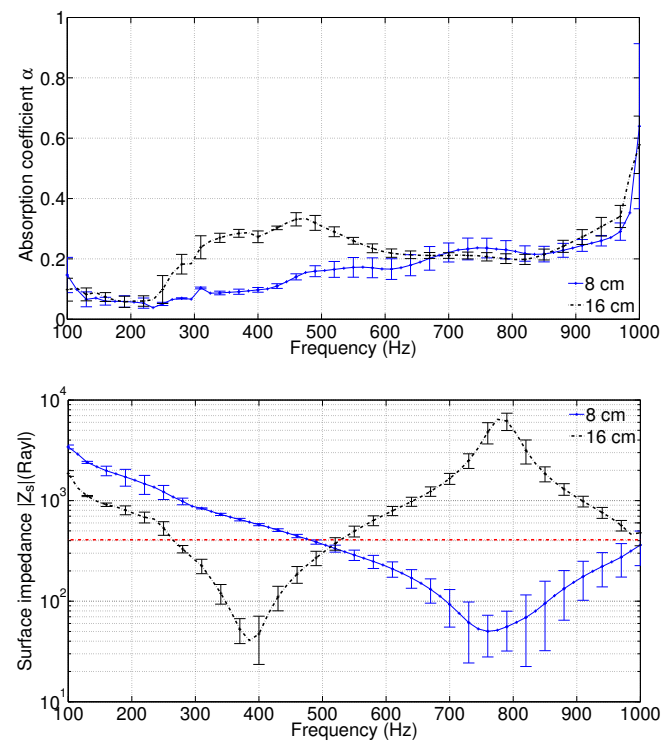

(b)

Figure 5: 8 and $16 \mathrm{~cm}$ thick Japanese spindle samples with $95 \%$ porosity in rigid backing condition: (a) absorption coefficient; (b) surface impedance modulus - Quantities measured in an impedance tube. Full line: average value; error bars: standard deviation; red dotted line: air characteristic impedance.

\section{Measurement of soil samples}

Perlite is an amorphous volcanous glass which expands greatly and becomes porous when heated above $850^{\circ} \mathrm{C}$. Superheated perlite is used as a soil amendment or alone as a medium for hydroponics, starting cuttings and green walls. Experimental results are reported for 8 and $16 \mathrm{~cm}$ thick samples of perlite (Fig. $3 \mathrm{~b})$. A sheet of tulle is used to keep the air/perlite interface perpendicular to the axis of the tube. Acoustic measurements are performed for four different geometrical arrangements of the same pebbles.

Figure 6 displays the real part of the effective speed of sound, the imaginary part of the acoustic wave number (attenuation) and the real part of the characteristic impedance of perlite sample versus frequency. The real part of the effective speed of sound increases monotonically from approximately 90 to $150 \mathrm{~m} / \mathrm{s}$ in the $100-1000 \mathrm{~Hz}$ frequency range (Fig. 6a). In that frequency range, perlite behaves as a dispersive medium with a speed of sound 2 to 4 times smaller than speed of sound in air. Attenuation is much larger than in plant sample and increases monotonically from 5 $\mathrm{Np} / \mathrm{m}$ at $100 \mathrm{~Hz}$ to $15 \mathrm{~Np} / \mathrm{m}$ at $1000 \mathrm{~Hz}$ (Fig. 6b). Characteristic impedance spectra of 8 and $16 \mathrm{~cm}$ thick samples differs strongly. From Fig. 6a, upper bound frequency for plane wave propagation in perlite sample is approximately equal to $300 \mathrm{~Hz}$. Therefore, although incident and reflected waves are plane in air, multimode propagation may occur in the sample above $300 \mathrm{~Hz}$ in particular if air/perlite inter-
295 
(a)

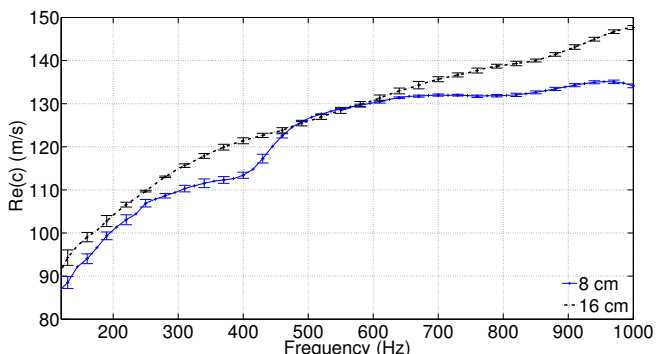

(b)

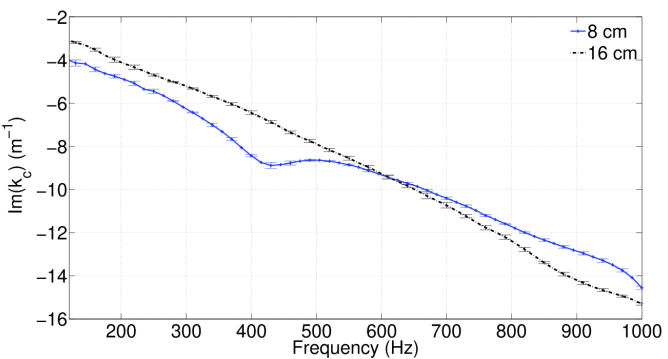

(c)

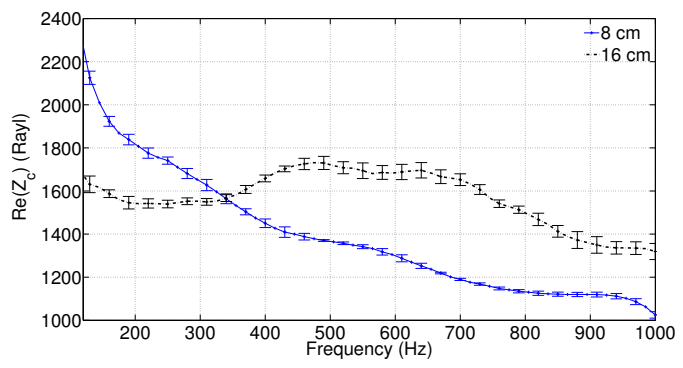

Figure 6: 8 and $16 \mathrm{~cm}$ thick perlite samples: (a) real parts of effective speed of sound; (b) imaginary part of acoustic wavenumber; (c) real part of nonnormalized characteristic impedance (b) versus frequency. Quantities measured in an impedance tube. Full line: average value; error bars: standard deviation. face is not perfectly perpendicular to the axis of the tube. In addition, this type of substrate may exhibit graded properties (density, porosity...) requiring more sophisticated model and inversion method which are beyond the scope of this paper. Several authors have reported that acoustic absorption was significantly modified by the gradient of properties in functionally graded polyurethane foams [22, 23].

Frequency spectra of the absorption coefficient and the surface impedance modulus of perlite samples in rigid backing condition are displayed in Figure 7. Absorption coefficient exhibits a resonancelike behaviour with frequency similar to the one previously reported for light substratum including perlite $[13,14]$. Absorption coefficient increases gradually from 0.2 at low frequency up to 0.8-0.9 at absorption peak and decreases slightly to a value close to 0.6-0.7 at higher frequencies. As for plant samples, quarterwavelength resonances of perlite samples are associ-
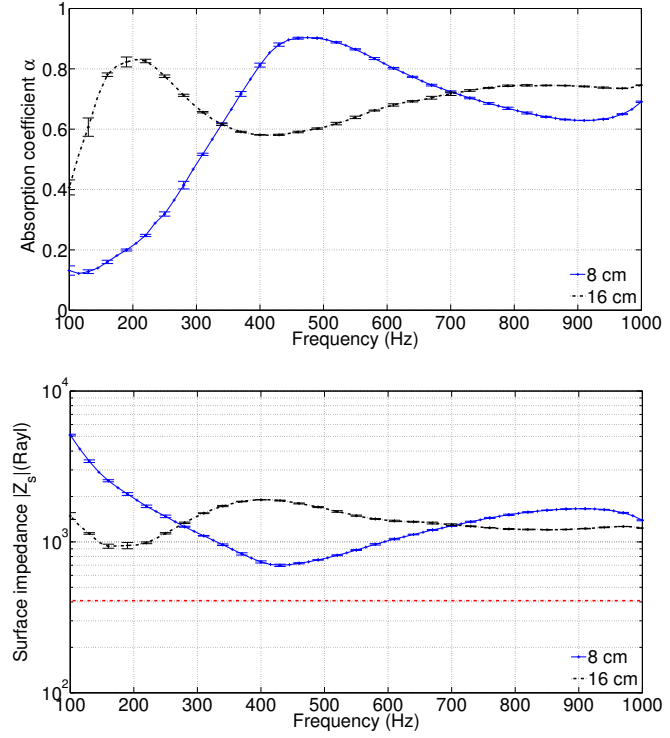

(b)

Figure 7: 8 and $16 \mathrm{~cm}$ thick perlite samples in rigid backing condition: (a) absorption coefficient; (b) surface impedance modulus. Quantities measured in an impedance tube. Full line: average value; error bars: standard deviation; red dotted line: air characteristic impedance.

ated to surface impedance minima at $433 \mathrm{~Hz}$ for $d=$ $8 \mathrm{~cm}$ and $166 \mathrm{~Hz}$ for $d=16 \mathrm{~cm}$. Due to the high attenuation of perlite (Fig. 6b), no other resonance or antiresonance appears at higher frequencies. Real and imaginary parts of surface impedance are of the same order of magnitude near quarter wave resonance and surface impedance modulus always remains larger than the characteristic impedance of air. Although impedance matching condition is not fulfilled in that case, it may be observed that the maxima of the acoustic absorption coefficient and the minima of the surface impedance modulus take place at nearby frequencies for both samples. An efficient absorption of incident acoustic energy by the perlite sample may be seen a two-step process which requires on one hand a limited impedance mismatch between the characteristic impedance of air and the surface impedance of the sample and, on the other hand, a high attenuation of the acoustic wave in the sample.

\section{Optimization of sound ab- sorption by green walls}

\subsection{Calculation method}

Acoustic absorption of samples composed of spindle, perlite and air layers may be calculated using matrix manipulation. This model relies upon the reduction of a real green wall system into the su- 
perposition of homogeneous layers representing plants, substrate or air separated by plane interfaces. Such simplified model may not simulate the whole complex interaction between air, plants and substrate or the natural gradient of porosity of plants related to illumination. However, it may be useful to identify the basic acoustic phenomena taking place when sound is absorbed by an air/plant/substrate multi-layered system. As spindle behaves as a homogeneous nondispersive medium, its transfer matrix $\mathbf{T}_{\text {plant }}\left(\omega, d_{p l}\right)$ for a layer of thickness equal to $d_{p l}$, is calculated using measured effective speed of sound and characteristic impedance (deduced from the transfer matrix of $8 \mathrm{~cm}$ thick spindle samples) together with Eq. (11). For perlite layers, matrix $\mathbf{T}_{\text {soil }}\left(\omega, d_{\text {so }}\right)$ measured for $d_{\text {so }}=8 \mathrm{~cm}$ or $d_{\text {so }}=16 \mathrm{~cm}$ is employed as it is. Transfer matrix of a slab of air $\mathbf{T}_{a i r}\left(\omega, d_{a i}\right)$ is calculated using Eq. (11) with $k=k_{0}$ and $Z_{c}=Z_{0}$. Transfer matrices of composite samples $\mathbf{T}_{\text {comp }}(\omega)$ used to determine absorption coefficient and surface impedance with Eq. (15) and (16) are expressed as follow:

$$
\mathbf{T}_{\text {comp }}(\omega)=\mathbf{T}_{\text {plant }}\left(\omega, d_{p l}\right)
$$

for green facade,

$$
\mathbf{T}_{\text {comp }}(\omega)=\mathbf{T}_{\text {plant }}\left(\omega, d_{p l}\right) \mathbf{T}_{a i r}\left(\omega, d_{a i}\right)
$$

for continuous living wall system,

$$
\mathbf{T}_{\text {comp }}(\omega)=\mathbf{T}_{\text {plant }}\left(\omega, d_{p l}\right) \mathbf{T}_{\text {soil }}\left(\omega, d_{\text {so }}\right)
$$

for type I modular living wall system and

$$
\mathbf{T}_{\text {comp }}(\omega)=\mathbf{T}_{\text {plant }}\left(\omega, d_{p l}\right) \mathbf{T}_{\text {soil }}\left(\omega, d_{\text {so }}\right) \mathbf{T}_{a i r}\left(\omega, d_{a i}\right)
$$

for type II modular living wall system.

To validate the calculation method, calculated absorption coefficient and surface impedance modulus are compared to measured ones in the $100-1000 \mathrm{~Hz}$ frequency range for three cases. The first test case is a $16 \mathrm{~cm}$ thick spindle layer with rigid backing condition. Calculated results are obtained by using the effective properties deduced from $8 \mathrm{~cm}$ thick spindle layer. They are compared to measurements in Fig. 8. A good agreement is found above $250 \mathrm{~Hz}$. At lower frequencies, noticeable differences observed for both absorption coefficient and surface impedance modulus are the consequence of effective properties discrepancies between measurements on 8 and $16 \mathrm{~cm}$ spindle samples (Fig. 4).

The second test case is a sample composed of a 8 $\mathrm{cm}$ thick spindle layer placed atop a $8 \mathrm{~cm}$ thick perlite layer. A very good agreement is obtained in the whole frequency range for both absorption coefficient and surface impedance modulus (Fig. 9). A high absorption coefficient is obtained in a broad frequency range when covering the soil with plants as previously reported in [14]. The broad absorption peak (a)

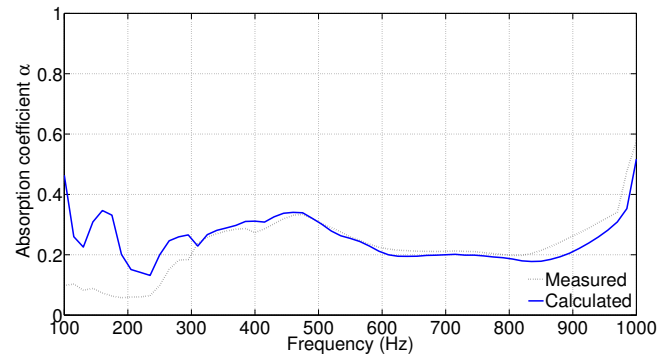

(b)

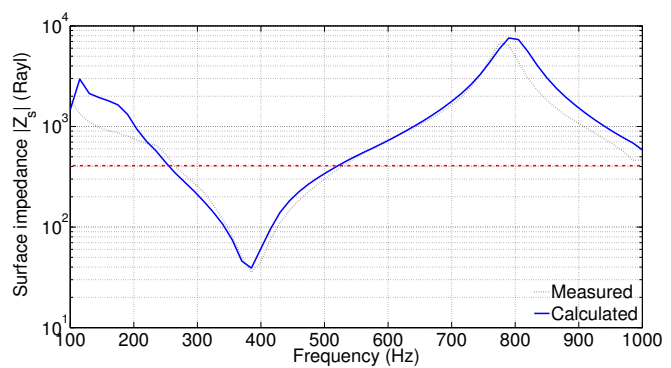

Figure 8: $16 \mathrm{~cm}$ thick spindle layer in rigid backing condition: (a) absorption coefficient; (b) surface impedance modulus. Red dotted line: air characteristic impedance.

(a)

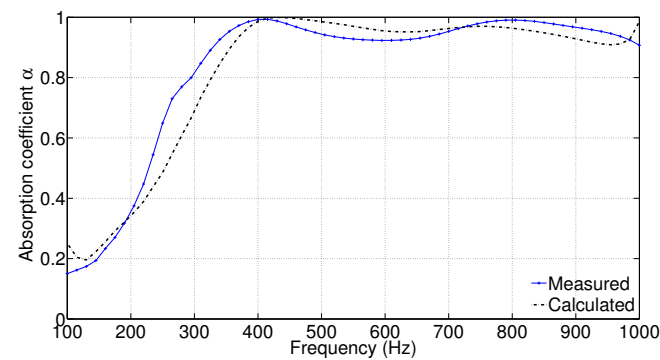

(b)

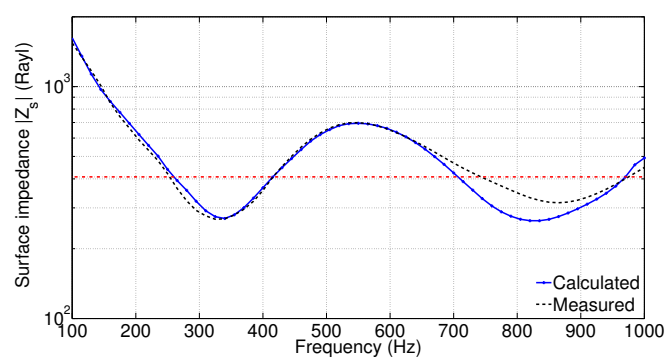

Figure 9: $8 \mathrm{~cm}$ thick spindle layer atop $8 \mathrm{~cm}$ thick perlite layer in rigid backing condition: (a) absorption coefficient; (b) surface impedance modulus. Red dotted line: air characteristic impedance. 


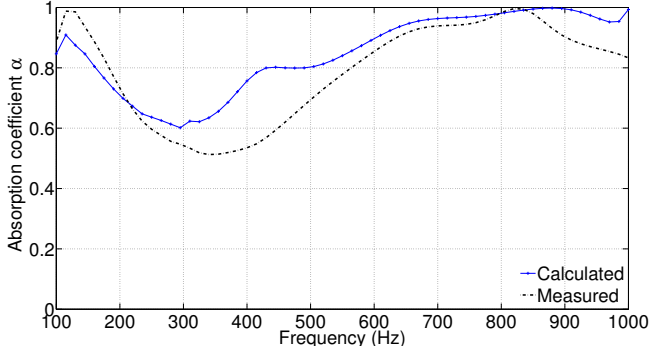

Figure 10: Absorption coefficient of a $8 \mathrm{~cm}$ thick spindle layer atop $8 \mathrm{~cm}$ thick perlite layer with a $16 \mathrm{~cm}$ thick air backing cavity.

between 400 and $1000 \mathrm{~Hz}$ is related to a good matching between the surface impedance of the sample and characteristic impedance of air $\left(Z_{0} \approx 410\right.$ Rayl $)$ in this frequency range. The presence of two minima of the surface impedance modulus located near 350 and $850 \mathrm{~Hz}$ suggests that at least two different physical phenomena contributes to this broadband impedance matching. This question is discussed in more details in section 5.4. When comparing both test cases, it appears that discrepancies appearing at low frequency in effective properties of plants affect significantly simulation results only if the overall absorption coefficient is low.

The last test case is constituted by the previous sample in front of a $16 \mathrm{~cm}$ thick air backing cavity. Despite some differences between simulated and measured absorption coefficient spectra (Fig. 10), the main variations with respect to the second test case (Fig. 9a) are correctly predicted by the transfer matrix model: first absorption peak shifts down from $400 \mathrm{~Hz}$ to approximately $130 \mathrm{~Hz}$; second absorption stays around $850 \mathrm{~Hz}$; absorption coefficient between absorption peaks decreases from 0.95 to 0.5-0.6.

\subsection{Sound absorption by green facade}

Green facade geometry may be schematically represented by a plant sample with rigid backing condition studied in section 3. Normal incidence absorption coefficient by green facade with $d_{p l}=8 \mathrm{~cm}$ and $d_{p l}=16 \mathrm{~cm}$ is displayed in Fig. 5a. Although thickness resonances occur in the $200-1000 \mathrm{~Hz}$ frequency range for this geometry, sound absorption remains limited by the weak acoustic attenuation in spindle. The effect of spindle layer thickness $d_{p l}$ on the absorption coefficient is displayed in Fig. 11 for $d_{p l}$ varying between 0 and $20 \mathrm{~cm}$. Simulations are not performed below $200 \mathrm{~Hz}$ to avoid aforementioned discrepancies. When $d_{p l} \leq 12 \mathrm{~cm}$, absorption coefficient is low $(<0.3)$ in the whole frequency range. For thicker plant layers, the absorption coefficient increases near thickness resonance frequencies to reach a maximum

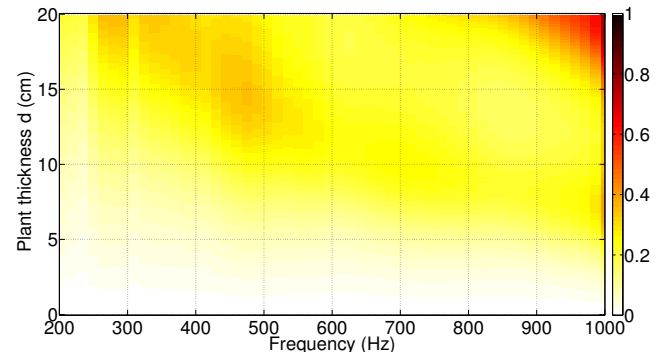

Figure 11: Green facade: variation of simulated absorption coefficient at normal incidence versus plant layer thickness.

(a)

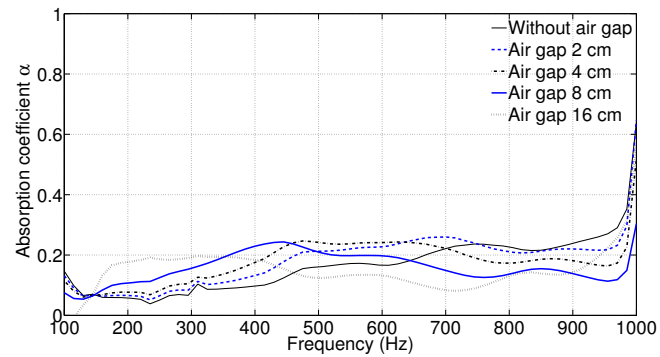

(b)

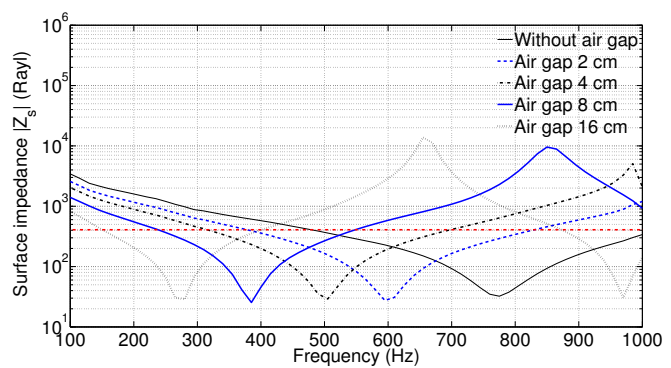

Figure 12: $8 \mathrm{~cm}$ thick spindle layer atop an air backing cavity of variable thickness: (a) absorption coefficient; (b) surface impedance modulus. Red dotted line: air characteristic impedance.

of 0.35 in the $300-500 \mathrm{~Hz}$ frequency range (quarter of wavelength resonance) and 0.6 above $900 \mathrm{~Hz}$ (three quarter of wavelength resonance).

\subsection{Sound absorption by continuous living wall system}

From an acoustical perspective, the main difference between continuous living wall system and green facade is the presence of an air gap separating plants from building wall. The effect of air gap of thickness $d_{a i}$ on the absorption coefficient and the surface impedance is illustrated in Figures 12 and 13 for $d_{p l}$ equal to 8 and $16 \mathrm{~cm}$ respectively. In the considered frequency range, both quarter of wavelength and three quarter of wavelength resonances shift down in frequency with increasing air gap thickness. Absorption coefficient is always less than 0.3 for $d_{p l}=8 \mathrm{~cm}$. It reaches 0.5 above $800 \mathrm{~Hz}$ for $d_{p l}=16 \mathrm{~cm}$ even when 
(a)
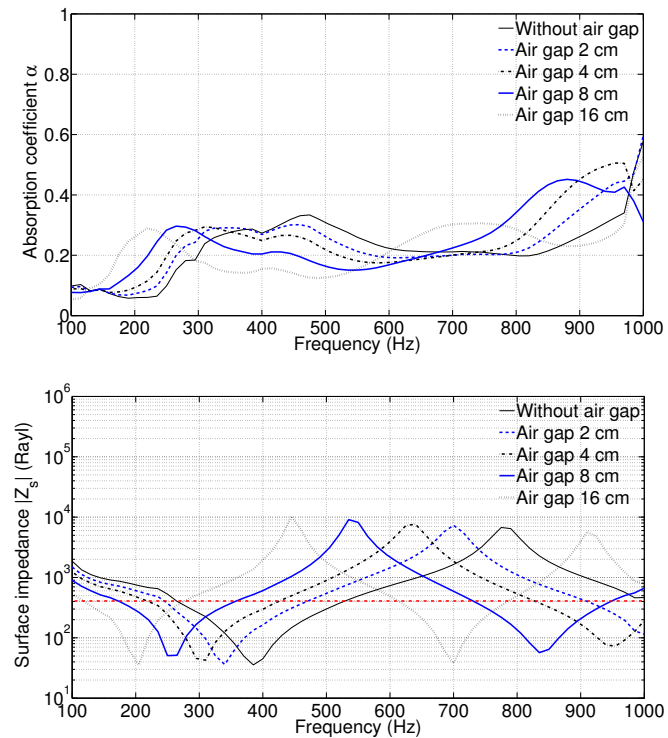

(b)

Figure 13: $16 \mathrm{~cm}$ thick spindle layer atop an air backing cavity of variable thickness: (a) absorption coefficient; (b) surface impedance modulus. Red dotted line: air characteristic impedance.

(a)

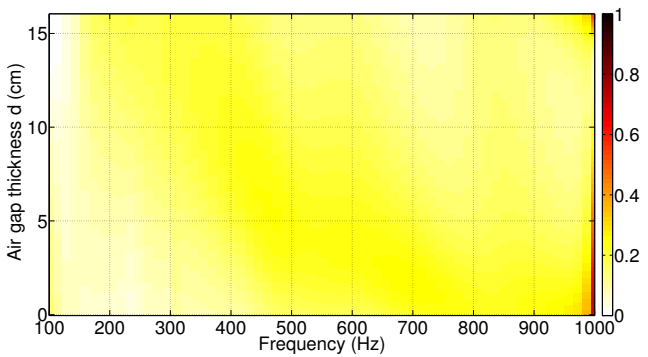

(b)

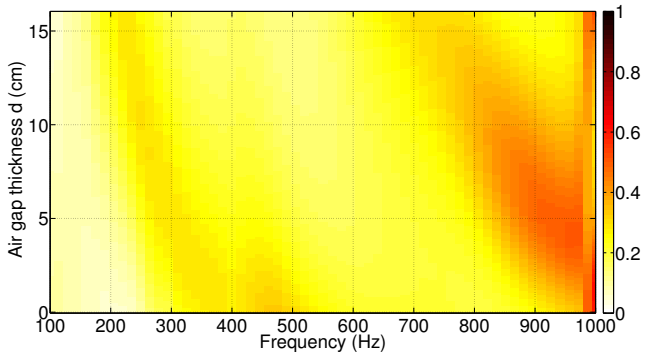

Figure 14: Continuous living wall system: variation of simulated absorption coefficient at normal incidence versus air gap thickness: (a) $8 \mathrm{~cm}$ thick spindle layer (b) $16 \mathrm{~cm}$ thick spindle layer. air gap thickness is small. More generally, the variation of absorption coefficient with air gap thickness $d_{p l}$ is displayed in Figure 14 for $d_{a i}$ varying between 0 and $16 \mathrm{~cm}$.

When comparing to green facade (Fig. 11), an increase of absorption coefficient is observed in the continuous living wall system with $d_{p l}=16 \mathrm{~cm}$ due to quarter of wavelength resonance between 200 and 500 $\mathrm{Hz}$ and to three quarter of wave length resonance between 700 and $1000 \mathrm{~Hz}$. Frequencies of these absorption peaks may be adjusted by an adequate choice of air gap thickness.

(a)
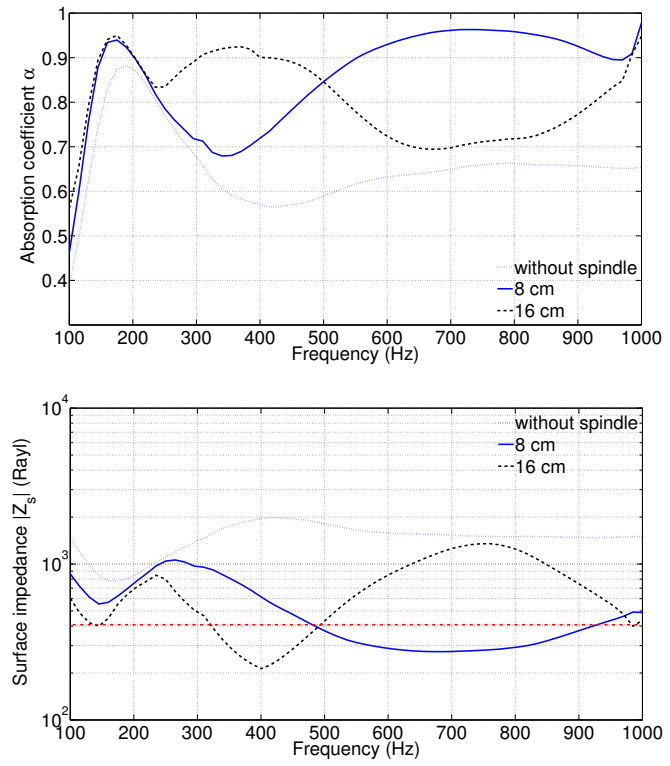

(b)

Figure 15: spindle layer of variable thickness atop $16 \mathrm{~cm}$ thick perlite layer: (a) absorption coefficient; (b) surface impedance modulus. Red dotted line: air characteristic impedance.

\subsection{Sound absorption by type type I modular living wall system}

The impact of plant layer thickness on sound absorption is studied for type I modular living wall systems composed of a spindle layer of variable thickness superposed on a perlite layer of constant thickness. Figure 15 displays the absorption coefficients and the surface impedance moduli of three different geometries in rigid backing condition: a $16 \mathrm{~cm}$ thick perlite layer, two samples composed of a 8 or $16 \mathrm{~cm}$ thick spindle layer placed on top of a $16 \mathrm{~cm}$ thick perlite layer. When $d_{s o}=16 \mathrm{~cm}$, the amplitude of the waves reflected by the backing surface of the perlite sample is small and the physical analysis is simplified. As mentioned in section 4, the absorption peak observed around $166 \mathrm{~Hz}$ for the perlite single layer corresponds to a quarter wavelength thickness resonance which improves impedance matching with air and facilitates energy transmission into the 
(a)
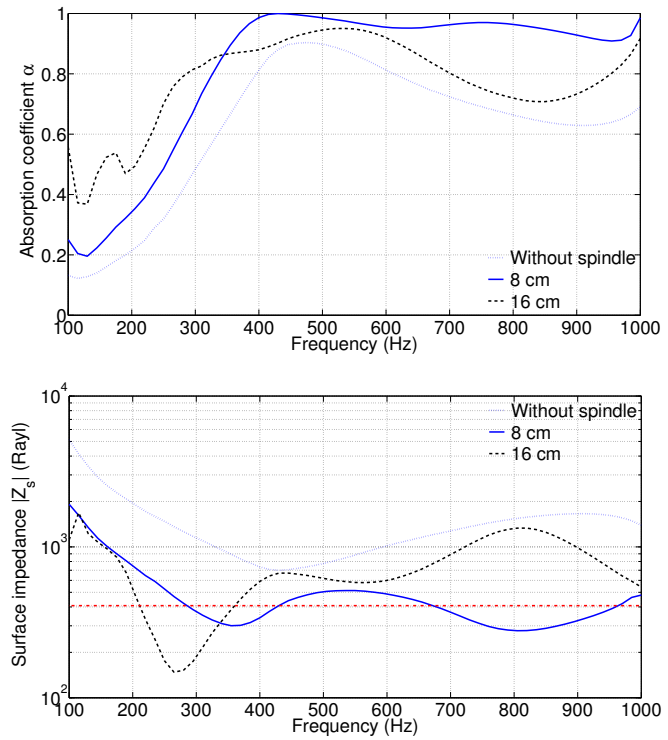

(b)

Figure 16: spindle layer of variable thickness atop $8 \mathrm{~cm}$ thick perlite layer: (a) absorption coefficient; (b) surface impedance modulus. Red dotted line: air characteristic impedance.

sample. When a spindle layer is added, total sample thickness increases and fundamental quarter wavelength resonance slightly shifts down in frequency. Around this mode, the surface impedance matches better air characteristic impedance due to the plant coverage and a higher absorption coefficient is obtained. Additional peaks of absorption coefficient and minima of sample surface impedance modulus are observed around $730 \mathrm{~Hz}$ and $365 \mathrm{~Hz}$ for spindle layer thickness of 8 and $16 \mathrm{~cm}$ respectively. At these frequencies, acoustic wavelength in spindle is approximately four times spindle layer thickness which suggests a quarter-wave transformer effect. In a quarter wave impedance transformer, a transmission line of length one-quarter wavelength is used to present at its input the dual of the impedance with which it is terminated. This properties is obtained when $Z_{\text {trans }}=\sqrt{Z_{\text {in }} Z_{\text {load }}}$ where $Z_{\text {trans }}$, $Z_{\text {in }}$ and $Z_{\text {load }}$ are the characteristic impedance of the transmission line, the input impedance and the load impedance respectively. For the considered case, $\left(Z_{i n}=Z_{0} \approx 410\right.$ Rayl) and $\left(Z_{\text {load }}=Z_{\text {cperlite }} \approx 1600\right.$ Rayl $)$. The characteristic impedance of the impedance transformer $Z_{\text {trans }}=\sqrt{Z_{0} Z_{\text {cperlite }}} \approx 810$ Rayl only differs by $20 \%$ from characteristic impedance of spindle. Therefore, additional peaks in absorption coefficient may be attributed to the impedance matching between air and perlite provided by spindle which operates as a quarter-wave transformer.

In the case of a thinner perlite layer, reflection from backing surface takes place and physical analysis becomes more complicated. As an example, absorption coefficients and surface impedance moduli are given in Figure 16 for 8 and $16 \mathrm{~cm}$ thick spindle layers atop of a $8 \mathrm{~cm}$ thick perlite layer in rigid backing condition. As previously, when adding a plant layer, quarter of wavelength resonance frequency shifts down from 433 $\mathrm{Hz}$ to $360 \mathrm{~Hz}$ when $d_{p l}=8 \mathrm{~cm}$, and to $273 \mathrm{~Hz}$ when $d_{p l}=16 \mathrm{~cm}$. However, the second minima of surface impedance modulus at $810 \mathrm{~Hz}\left(d_{p l}=8 \mathrm{~cm}\right)$ and $566 \mathrm{~Hz}\left(d_{p l}=16 \mathrm{~cm}\right)$ does not correspond anymore to a quarter of wavelength in spindle layer due to reflection from backing surface. At these minima, the surface impedance modulus is higher for $d_{p l}=16 \mathrm{~cm}$ $\left(Z_{s} \approx 590\right.$ Rayl) than for $d_{p l}=8 \mathrm{~cm}\left(Z_{s} \approx 280\right.$ Rayl). Consequently, the broadband impedance matching and the absorption coefficient obtained for $d_{p l}=8 \mathrm{~cm}$ are degraded when the plant thickness is increased to $16 \mathrm{~cm}$.

A more complete representation of the absorption coefficient of a type I modular living wall system composed of a spindle layer of variable thickness atop of a 8 or $16 \mathrm{~cm}$ thick perlite layer is given in Figure 17 . This green wall system exhibits a much better acoustic absorption than green facade and continuous living wall because of soil layer attenuation. Thus, for a 8 $\mathrm{cm}$ thick perlite layer, efficient absorption $(\alpha>0.9)$ is obtained in the $350-1000 \mathrm{~Hz}$ frequency range when $8 \mathrm{~cm} \leq d_{p l} \leq 10 \mathrm{~cm}$ under normal incidence. A more realistic sound field conditions such as diffuse field will tend to smooth out the absorption levels over the frequency range and reduce the maximum level of absorption. For a thicker perlite layer $\left(d_{s o}=16 \mathrm{~cm}\right)$, efficient absorption is observed in a narrower frequency range and the acoustic absorption coefficient remains higher than 0.5 in the whole frequency range for all plant layer thicknesses.

\subsection{Sound absorption by type type II modular living wall system}

This section focuses on the effect, on the acoustic absorption, of an air gap introduced between the plantsoil bi-layer and the building wall. A previous work has reported that the addition of a backing air cavity was an efficient way to increase sound reduction index of green roofs [24]. Three different configurations with an air gap of variable thickness are simulated: 8 or $16 \mathrm{~cm}$ thick spindle layer atop of $8 \mathrm{~cm}$ thick perlite layer; $8 \mathrm{~cm}$ thick spindle layer atop of $16 \mathrm{~cm}$ thick perlite layer. Corresponding absorption coefficients and surface impedance moduli in rigid backing condition are given in Figures 18 to 20 . For all cases, the increase of air gap thickness induces a down-shift of the lowest (quarter of wavelength) resonance frequency with variable effects on absorption coefficient according to the plant-soil bi-layer geometry. In the first case $\left(d_{p l}=8 \mathrm{~cm}, d_{s o}=8 \mathrm{~cm}\right)$, initial broadband absorption band tends to split into 
(a)

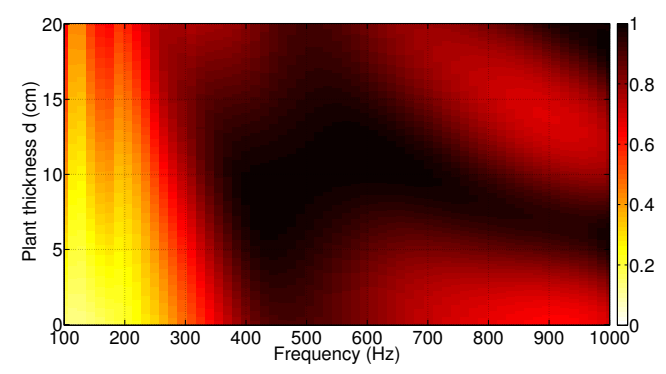

(b)

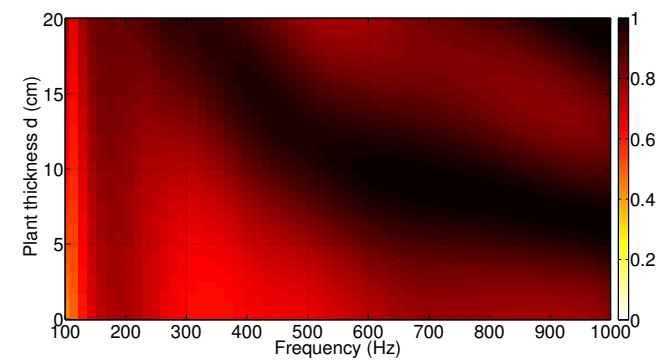

Figure 17: Type I modular living wall system: variation of simulated absorption coefficient at normal incidence versus spindle layer thickness: (a) $8 \mathrm{~cm}$ thick perlite layer (b) $16 \mathrm{~cm}$ thick perlite layer.

(a)

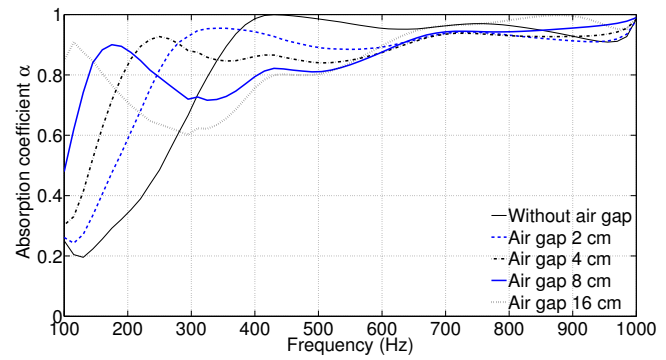

(b)

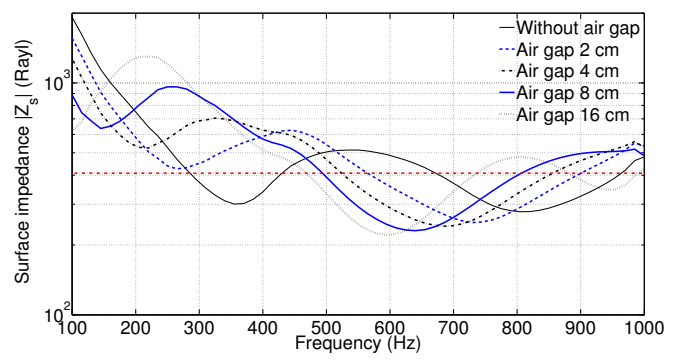

Figure 18: $8 \mathrm{~cm}$ thick spindle layer atop $8 \mathrm{~cm}$ thick perlite layer with air backing cavity of variable thickness: (a) absorption coefficient; (b) surface impedance modulus. Red dotted line: air characteristic impedance. (a)
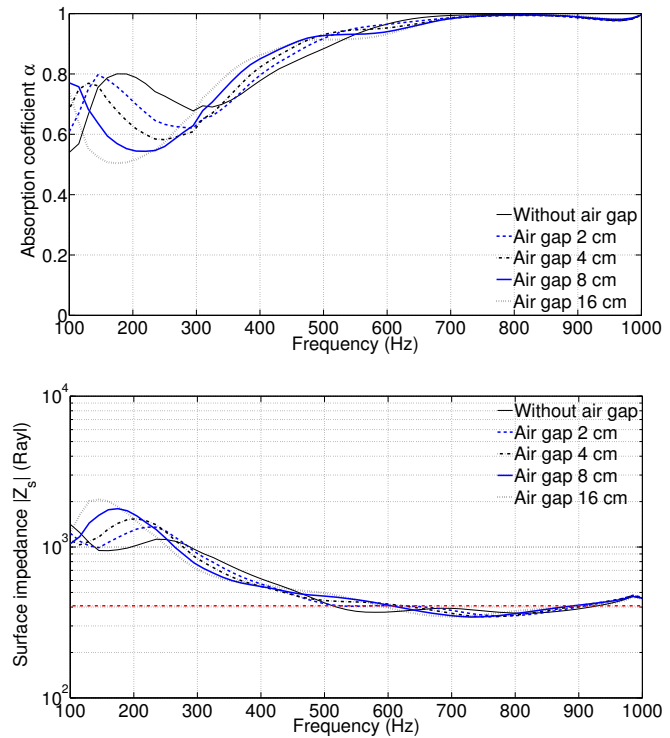

(b)

Figure 19: $8 \mathrm{~cm}$ thick spindle layer atop $16 \mathrm{~cm}$ thick perlite layer with air backing cavity of variable thickness: (a) absorption coefficient; (b) surface impedance modulus. Red dotted line: air characteristic impedance.

(a)

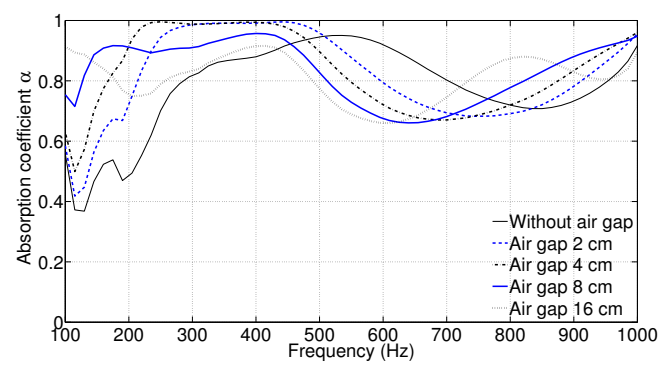

(b)

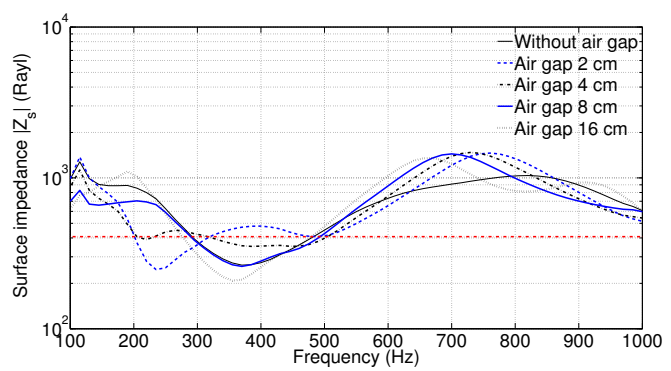

Figure 20: $16 \mathrm{~cm}$ thick spindle layer atop $8 \mathrm{~cm}$ thick perlite layer with air backing cavity of variable thickness: (a) absorption coefficient; (b) surface impedance modulus. Red dotted line: air characteristic impedance. 
two separate absorption peaks with increasing air gap thickness (Fig. 18a). Absorption is degraded between these two peaks due to the increase of the surface impedance modulus (Fig. 18b). In the second case $\left(d_{p l}=8 \mathrm{~cm}, d_{s o}=16 \mathrm{~cm}\right)$, only the low frequency absorption peak slightly shifts down in frequency with increasing air gap thickness (Fig. 19a). Above $300 \mathrm{~Hz}$, the absorption coefficient and the impedance surface modulus (Fig. 19b) are not affected by the air gap. The last case $\left(d_{p l}=16 \mathrm{~cm}, d_{s o}=8 \mathrm{~cm}\right)$ is characterized by a low frequency broad absorption peak which shifts down in frequency with increasing air gap thickness (Fig. 19a). Maximal absorption is obtained between 300 and $470 \mathrm{~Hz}$ for a $2 \mathrm{~cm}$ thick air gap and between 230 and $430 \mathrm{~Hz}$ for a $4 \mathrm{~cm}$ thick air gap.

The variation of absorption coefficient frequency spectrum with air gap thickness is displayed in Figure 21 for the three considered plant-soil configurations. The second configuration $\left(d_{p l}=8 \mathrm{~cm}, d_{s o}=16 \mathrm{~cm}\right)$ is characterized by a high absorption coefficient above $400 \mathrm{~Hz}$ for any air gap thickness. The third configuration $\left(d_{p l}=16 \mathrm{~cm}, d_{s o}=8 \mathrm{~cm}\right)$ displays a broad absorption peak below $450 \mathrm{~Hz}$ for $2 \mathrm{~cm} \leq d_{p l} \leq 8 \mathrm{~cm}$. Thus, a high absorption coefficient may be obtained in a broader frequency range between 200 and 1000 $\mathrm{Hz}$ by combining these two configurations in a single modular living wall system.

\subsection{Summary and conclusion}

Measurement of the effective acoustic properties of plants and soils have been combined with transfer matrix method to simulate the acoustic absorption coefficient by different types of green walls. Results show that an adequate choice of constituents and geometry may result in an efficient absorption of sound in a broad frequency range due to two main mechanisms: the thickness resonances of the wall structure; the quarter wave transformer effect provided by the plant layer between air and soil layer. Among different green wall types, modular living wall systems display higher sound absorption performance than continuous living wall systems or green facades with an absorption coefficient larger than 0.9 in a frequency bandwidth that may reach $600 \mathrm{~Hz}$. The proposed approach could also be used to simulate the effect of environmental (moisture content) or seasonal (deciduous, semi-deciduous or semi-evergreen plants) changes on sound absorption.

\section{Acknowledgement}

Support of this work by ADEME, Yncrea Group and "Hauts-de-France" region is greatly acknowledged. The authors would also like to thank the anonymous reviewers for their helpful and relevant comments. (a)

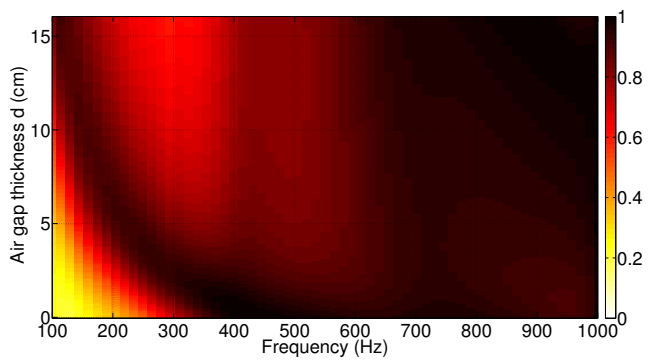

(b)

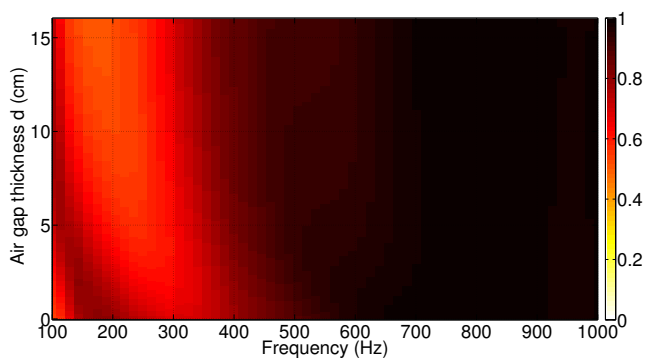

(c)

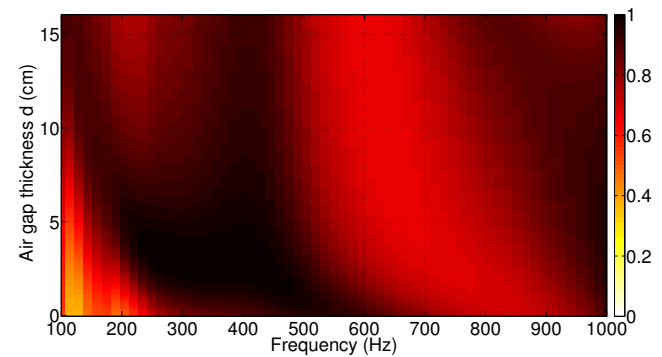

Figure 21: Type II modular living wall system: variation of absorption coefficient at normal incidence versus air gap thickness: (a) $8 \mathrm{~cm}$ thick spindle layer atop of $8 \mathrm{~cm}$ thick perlite layer; (b) $8 \mathrm{~cm}$ thick spindle layer atop of $16 \mathrm{~cm}$ thick perlite layer; (c) $16 \mathrm{~cm}$ thick spindle layer atop of $8 \mathrm{~cm}$ thick perlite layer. 


\section{References}

[1] R. Francis, J. J. Lorimer: Urban reconciliation ecology: The potential of living roofs and walls. J Environ Manag 92 (2011) 1429-1437.

[2] T. Pugh, A. MacKenzie, J. Whyatt, C. Hewitt: Effectiveness of Green infrastructures for improvement of air quality in urban street canyons. J Environ Manag 92 (2011) 1429-1437.

[3] E. Alexandri, P. Jones: Temperature decreases in an urban canyon due to green walls and green roofs in diverse climates. Build Environ 43 (2008) 480-493.

[4] N. H. Wong, A. Y. K. Tan, P. Y. Tan, K. Chiang, K., N. C. Wong: Acoustics evaluation of vertical greenery systems for building walls. Build Environ 45 (2010) 411-420.

[5] T. van Renterghem, M. Hornikx, J. Forssen, D. Botteldooren: The potential of building enveloppe greening to achieve quietness. Build Environ 61 (2013) 34-44.

[6] T. van Renterghem, M. Hornikx, M. Smyrnova, P. Jean, J. Kang, D. Botteldooren: Road traffic noise reduction by vegetated low noise barriers in urban streets. Proceedings of Euronoise 2012, (2012).

[7] M. Manso, J. Castro-Gomes: Green wall systems: A review of their characteristics. Renewable and Sustainable Energy Reviews 41 (2015) 863-871.

[8] T. Shimizu, T. Matsuda, Y. Nishibe, M. Tempo, K. Yoshitani, Y. Azumi: Suppression of diffracted sounds by green walls. Noise Control Engr J 64 (2016) 142152.

[9] Z. Azkorra, G. Pérez, J. Coma, L. F. Cabeza, S. Bures, J. E. Álvaro, A. Erkoreka, M. Urrestarazu: Evaluation of green walls as a passive acoustic insulation system for buildings. Appl Acoust 89 (2015) 46-56.

[10] International Standard ISO 354: Acoustics - Measurement of sound absorption in a reverberation room, 2011.

[11] International Standard ISO 10534-2: Acoustics Determination of sound absorption coefficient and impedance in impedance tubes - Part 2: Transferfunction method, 1998.

[12] H.-S. Yang, J. Kang, C. Cheal: Random-incidence absorption and scattering coefficients of vegetation. Acta Acust united Ac 99 (2013) 379-388.

[13] K. V. Horoshenkov, A. Khan, H. Benkreira: Acoustics properties of low growing plants. J Acoust Soc Am 133 (2013) 2554-2565.

[14] H. Benkreira, K. V. Horoshenkov, A. Khan, A. Mandon, R. Rohr: The effect of drying on the acoustic absorption of novel green noise insulation. Proceedings of European Drying Conference - EuroDrying (2011).

[15] L. Ding, T. van Renterghem, D. Bottledooren: Sound absorption of porous substrates covered by foliage: experimental results and numerical predictions. J Acoust Soc Am 134 (2013) 4599-4609.

[16] M. Connelly, M. Hodgson: Experimental investigation of sound transmission of vegetated roofs. Appl Acoust 74 (2013) 1136-1143.
[17] E. Attal, N. Côté, G. Haw, G. Pot, C. Vasseur, T. Shimizu, C. Granger, C. Croënne, B. Dubus: Experimental characterization of foliage and substrate samples by the three-microphone two-load method. Proceedings of Inter-noise 2016, (2016).

[18] H. Utsuno, T. Tanaka, T. Fujikawa, A. F.Seybert: Transfer function method for measuring characteristic impedance and propagation constant of porous materials. J Acoust Soc Am 86 (1989) 637-643.

[19] O. Doutres, Y. Salissou, N. Atalla, R. Panneton: Evaluation of the acoustic and non-acoustic properties of sound absorbing materials using a three-microphone impedance tube. Appl Acoust 71 (2010) 506-509.

[20] Y. Salissou, R. Panneton, O. Doutres: Complement to standard method for measuring normal incidence sound transmission loss with three microphones. J Acoust Soc Am 131 (2012) 216-222.

[21] International Standard ISO 10140-2: Laboratory measurement of sound insulation of building elements - Part 2: Measurement of airborne sound insulation, 2010.

[22] O. Doutres, N. Atalla: Sound absorption properties of functionally graded polyurethane foam. Proceedings of Inter-noise 2012, (2012).

[23] P. Schrader, F. Duvigneau, R. Orszulik, H. Rottengruber, U. Gabbert: A numerical and experimental study ion the noise absorption behavior of funtionally graded materials considering geometrical and material influences. Proceedings of Inter-noise 2016, (2016).

[24] L. Galbrun, L. Scerri: Sound insulation of lightweight extensive green roofs. Build Environ 116 (2017) 130139. 